\title{
Gender based Violence in Nigeria: A Review of Attitude and Perceptions, Health Impact and Policy Implementation
}

\author{
Article by Stella Chinyere Okwundu \\ Master's in Public Health, Texila American University \\ E-mail: s.okwundu@gmail.com
}

\begin{abstract}
Gender based violence $(G B V)$ is a fundamental public health and human rights concern across the world. This article provides a systematic review of attitude and perception of $G B V$, heath impact and policy implementation in Nigeria. Materials to be reviewed were selected based on search criteria which are relevant to the study at hand. Only 21 articles met the set criteria. Intimate partner violence (wife beating) and rape were the categories of violence being studied. Result showed that wife being is widely justified in Nigeria by the women if they go out without telling him, being disrespectful, neglects the children and burns his food. The men also justified GBV as a means of earning respect as the women are the weaker sex. Rape is considered a crime but the perception of what constitutes rape is poor as marital rape and rape by boyfriends and man friends are not considered as rape. GBV has physical, mental and social health impact among the victims. Policy implementation of GBV is considered to be poor in Nigeria. Recommendations were made based on the findings made from review of the articles.
\end{abstract}

Keywords: Gender based violence, rape, intimate partner violence, attitude, perception, policies and policy implementation, Nigeria.

\section{Introduction}

\section{What is gender based violence}

Gender-based violence (GBV) is a term that describes any harmful act that is carried out against a person's will, and the act is based on socially attributed differences between males and females within the context of a specific society (Uwameiye and Iserameiya, 2013).

The United Nations (UN) in the convention on the elimination of all forms of discrimination against women defined gender based violence as any action that causes physical, sexual or psychological injury or suffering to women with the inclusion of acts of coercion (Bott et al, 2005).

GBV is rooted in gender inequality which is excused by the communities, laws and institutions hence it is not just a manifestation of gender inequality but an enforcement of GBV. Around the world, women are the major victims of GBV hence the term violence against women is used interchangeably with GBV as most gender-based violence is inflicted by men on women and girls. Although men and boys can be victims/survivors of some types of GBV For instance, men who have sex with men can become victims of physical or verbal attacks for violating the predominant concepts of masculinity. Men can also suffer violence in the family - by partners or children (Bloom, 2008). 
DOI: $10.21522 / \mathrm{TIJPH} .2013 .05 .04$. Art042

ISSN: $2520-3134$

\section{Forms of gender based violence}

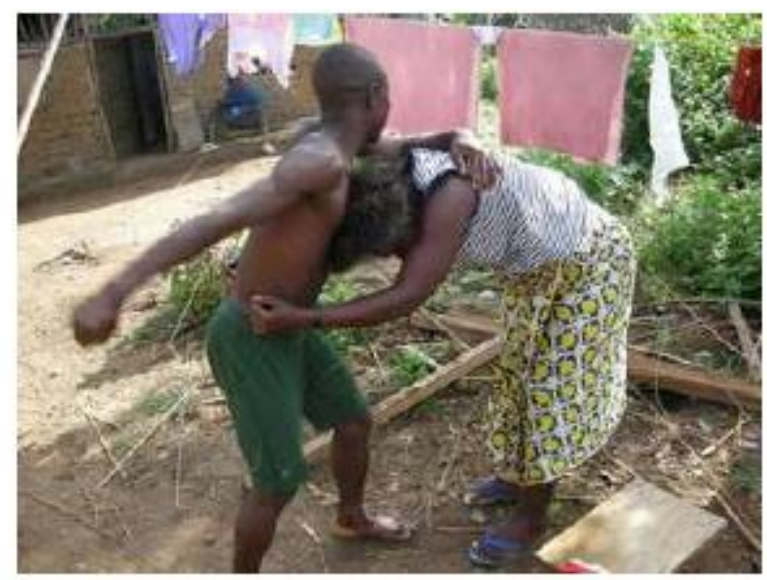

- Physical violence: Physical abuse may include spitting, scratching, biting, grabbing, shaking, shoving, pushing, restraining, throwing, twisting, slapping (with open or closed hand), punching, choking, burning, and/or use of weapons (e.g., household objects, knives, guns) against the victim. The physical assaults may or may not cause injuries.

- Sexual violence: This is the sexual violation of an individual by an individual or a group of people. Generally sexual violence occurs mainly at home but could also occur in other settings. The perpetuator is most often known by the abuser and could come from any strata of the society. Sexual violence include rape, forced marriage, female genital mutilation, prostitution, sexual harassment, forced pregnancy, forced abortion and forced sterilization (Ganley, 1998).

- Psychological violence: This includes threat to life, emotional violence, isolation and controlling victim's access to all the family resources: time, transportation, food, clothing, shelter, insurance, and money (Ganley, 1998).

\section{Levels of gender based violence}

Gender based violence can also be perpetuated at three levels

- Domestic violence: This refers to a pattern of abusive acts perpetuated by an individual in a close relationship which occurs in multiple episodes during the relationship. This is the most prevalent form of gender based violence and it perpetuated by intimate male partners (Heise et al, 2002). Domestic violence takes the form of or a combination of physical assault, psychological, and sexual violence. Examples include battery, rape, female genital mutilation, name calling/degrading, and derogatory comments, isolation (Jekayinfa, 2002). Domestic violence is also known as intimate partner violence (Heise et al, 2002).

- Community based violence: Physical, sexual and psychological violence occurring within the general community include battery, rape, sexual assault, sexual harassment and intimidation in school or work, forced treatments and abusive medication, the exploitation and commercialization of women's bodies which is related to increased poverty that is mainly a result of unbridled economic liberalism. 


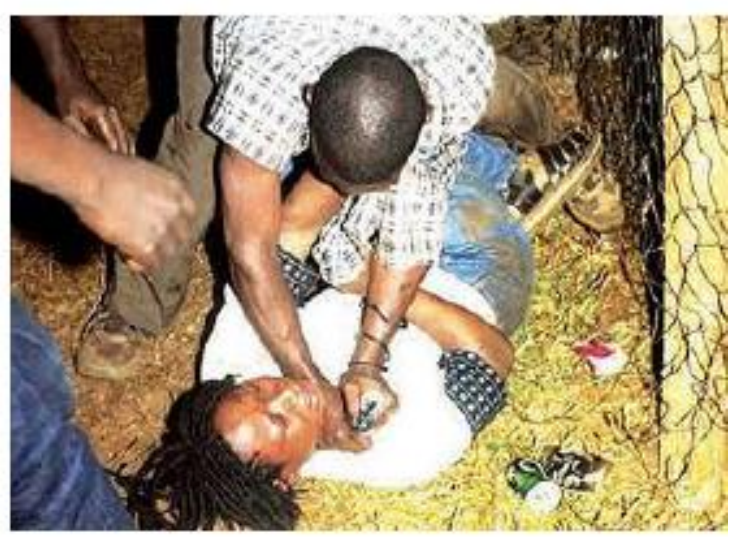

- State perpetuated GBV: Physical, sexual and psychological violence are too often perpetrated or tolerated by states that priorities custom or tradition over the respect of fundamental freedom. In some countries, the rise of religious fundamentalism is extremely disturbing with regards women's right to their economic autonomy and their freedom of choice. The social exclusion of women is so great that it constitutes a new form of apartheid. Women are considered second class beings, of lesser value, deprived of their fundamental rights. Violence against women is also exercised as a weapon of war in situations of armed conflict. It has many forms including murder, rape, sexual slavery, hostage taking and forced pregnancy.

\section{The research problem}

The 2013 National Demographic Health Survey indicates that 28\% of women are experiencing GBV and it cuts across all socio-economic and cultural backgrounds. Forms of violence span from forced marriage to physical, mental and sexual assault. According to the UNFPA, the incidence of GBV is growing at an alarming rate in Nigeria especially in the North-Eastern Region due to the activities of insurgents. About 3 in 10 Nigerian women have experienced physical violence by the age of 15 . There is a lot of silence on the issues of GBV both in the society and among victims. Hence the article seeks to search existing literatures to identify reported attitudes and perceptions of Nigerians towards GBV and health impact to the victims of GBV. It also seeks to know what policies are in place to reduce the growing trend of GBV and the level of implementation of these policies in Nigeria. Knowledge gained from this article would show new frontiers for research to help curb GBV in Nigeria.

\section{Objectives}

To review literatures to assess attitude, perception and health impact of GBV in Nigeria and to review existing policies and level of implementation of GBV policies in Nigeria.

\section{Methodology}

\section{Data sources and search procedure}

Materials on GBV in Nigeria which was published within the last 10 years from electronic databases such as Google Scholar, Medline and PubMed were searched in May 2016. The search followed a Boolean procedure which led to initial selection of materials based on the appearance of any of the search terms related to GBV, any of the search terms related to attitude, perception, health impact and any of the search terms related to policies and policy implementation. Full articles and abstracts of studies identified through the process stated above were reviewed to check if inclusion of the targeted search term had substance or is in tandem with the focus of the article. It was also determined if the articles sampling universe was sufficiently generalizable. 
DOI: $10.21522 / \mathrm{TIJPH} .2013 .05 .04 . \mathrm{Art} 042$

ISSN: $2520-3134$

\section{Inclusion and exclusion criteria}

The study followed the principles of a systematic review (Mulrow, 1994) in defining explicit inclusion criteria for studies considered during the review. Five core themes structured such inclusion criteria: GBV; attitude; perception; health impact; policies and policy implementation. For the purposes of this review, an article which addresses any of the five thematic areas was accepted. Articles of GBV that is not related to Nigeria i.e. participants from the study are not Nigerians or study was done in places other than Nigeria was excluded from the study. Articles that are published in languages other than English Language was also excluded from the review.

\section{Basic findings}

The search for literatures on the internet for the attitude, perception, health impact and policy implementation of gender based violence in Nigeria yielded twenty-one (21) articles that met the criteria for the review. Two main categories of gender based violence were commonly studied: Intimate partner violence and community based violence. Eight (8) of the articles reviewed focused on attitude and perception of women to Intimate partner violence, two (2) articles focused on attitude and perception of men to Intimate partner violence although one out of the two articles looked at gender based violence generally. Four articles focused on the health impact of intimate partner violence and five (5) articles focused on the policy implementation of GBV.

Community based violence that was reviewed was rape and female genital mutilation and two of the articles focused on rape and one focused on female genital mutilation.

\section{Study design}

Cross sectional studies was employed for fifteen (15) articles under review where structured questionnaires were used to assess the attitude and perception on gender based violence and health impact of GBV. Two of the articles employed focus group discussions and in depth interview to study attitude and perception on gender based violence and policy formulation and implementation of gender policy in a community respectively. One of the articles combined cross sectional study, focus group and in depth interview in the study of attitude and perception on gender based violence. Secondary literatures were also reviewed to assess implementation of gender policy in Nigeria since there was no other article that assesses policy implementation of GBV in Nigeria.

\section{Sampling and response rate}

True random sampling that is generalizable to a larger population was achieved in only three of the studies identified through this review. In half of the studies, specific health centers, hospitals and towns were purposefully selected based on logistics, convenience or other unspecified reasons.

Majority of the articles did not report response rate while the ones that reported recorded a high response rate. This could be attributed to the researchers being a member of the places being studied.

\section{Attitude and perception towards gender based violence}

The main findings on the attitude and perception of Nigerians from the six geopolitical zones of the country are outlined in Table 1 . Most of the articles reviewed focused on Intimate partner violence particularly wife battery (only a few focused on GBV perpetuated among youths but restricted the study to students in the universities.

Despite these limitations, certain trend can be detected in relation to the attitude and perception of Nigerians to GBV. It is observed that gender based violence is perceived by the participants to occur in almost every home. It is observed that in every part of the country that gender based violence is justified for reasons such as going out without telling him, being disrespectful, arguing with him, refusing him sex, and burning food by a large percentage of women who participated in the study ranging from $42-62 \%$. The men also justified GBV based on the same reason the women justified GBV. It is explained that wife beating 
is the way to assert authority and make the women responsible as the women are the weaker sex and hence needs to be controlled. Unfortunately, the women in the studies reviewed also view themselves in the same light as the men's view. The Hausa ethnic group is more likely to justify GBV than any other ethnic group.

The women in the studies reviewed also have the attitude of not reporting the perpetrators of GBV to the police, a majority would rather keep it to themselves or report to close family, friends or to their religious leaders.

Majority of the articles reviewed on GBV among youths were among university students and rape was the major GBV of focus. The participants perceive rape to be a crime due to the dignity of the raped being violated, violation of the fundamental rights and exposing of the victim to unwanted pregnancy and HIV/AIDs. However forced sex by the boyfriend or man friend is not considered as rape. This could also be the reason why the participants of IPV do not recognize marital rape.

The women in the studies reviewed will not consider exiting a violent marriage because of the children, the belief that the perpetrator would change, the fear of being a burden to parents and the fear of being called a prostitute (Ilika, 2005; Fawole et al., 2005). 


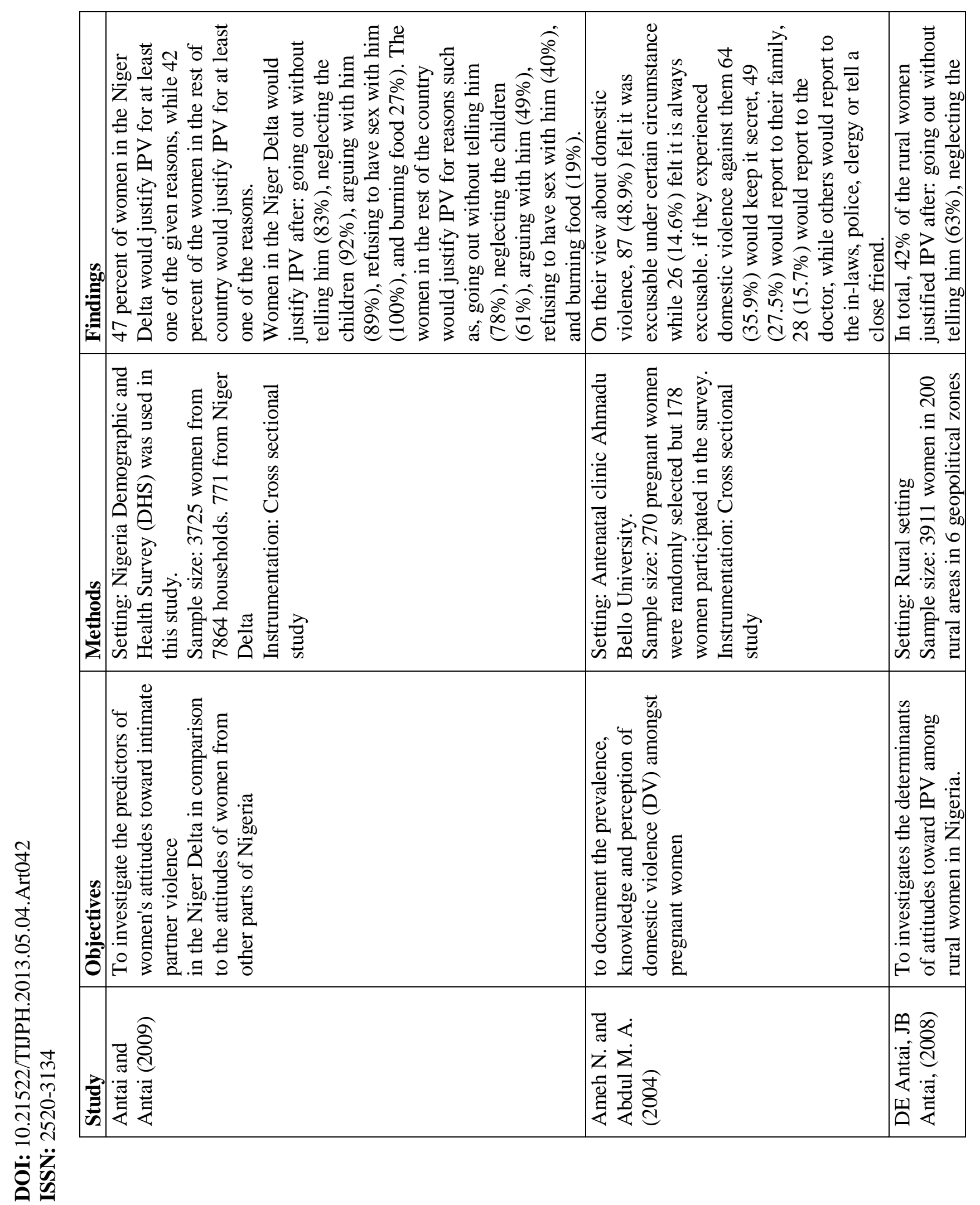




\begin{tabular}{|c|c|c|}
\hline 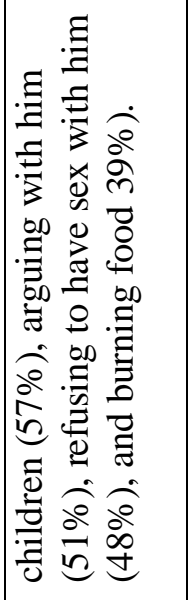 & 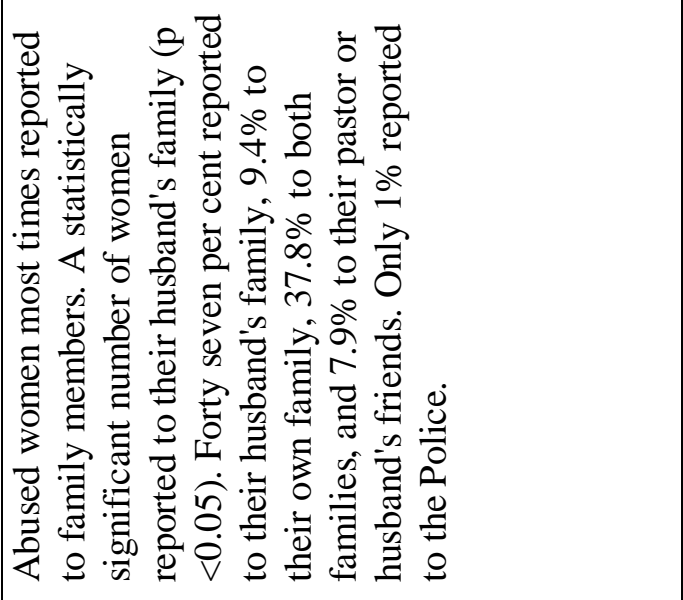 & 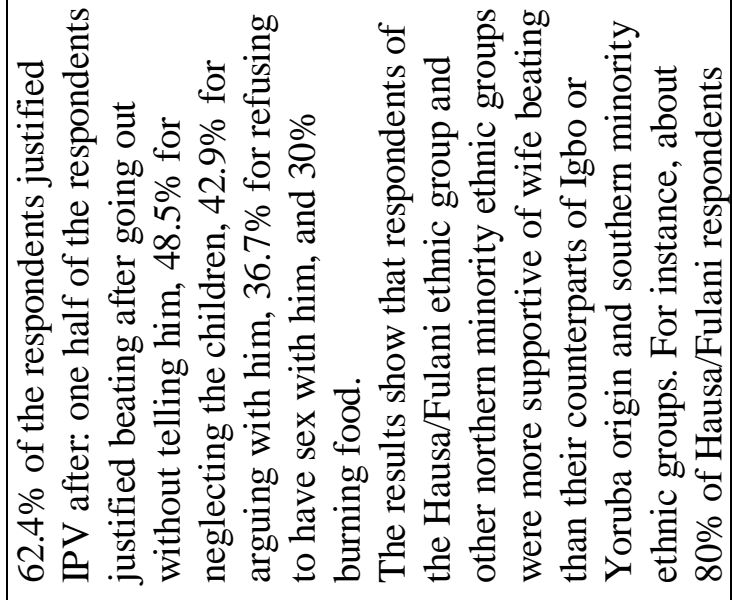 \\
\hline \multirow[t]{3}{*}{ 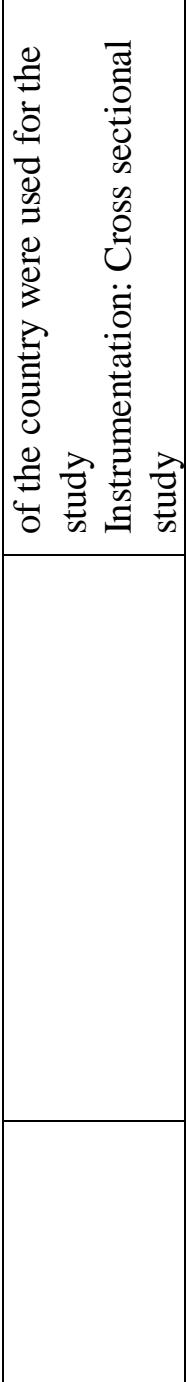 } & 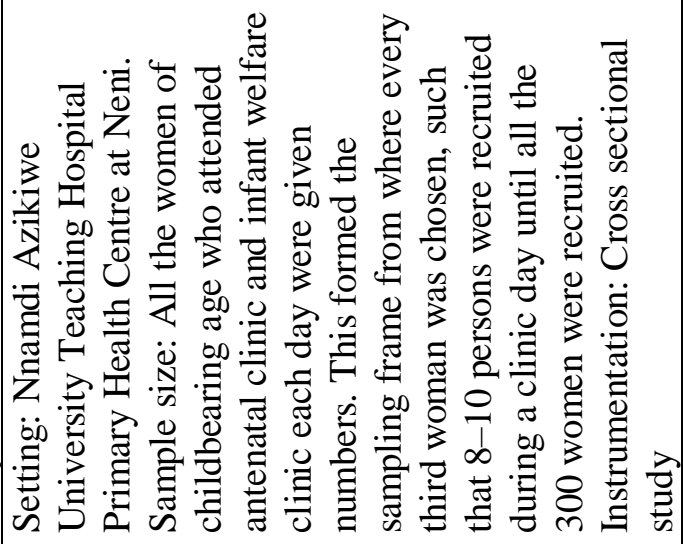 & 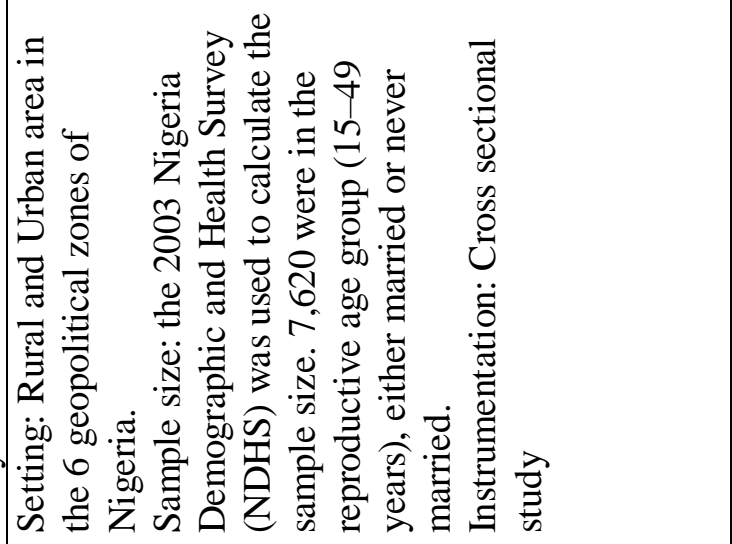 \\
\hline & 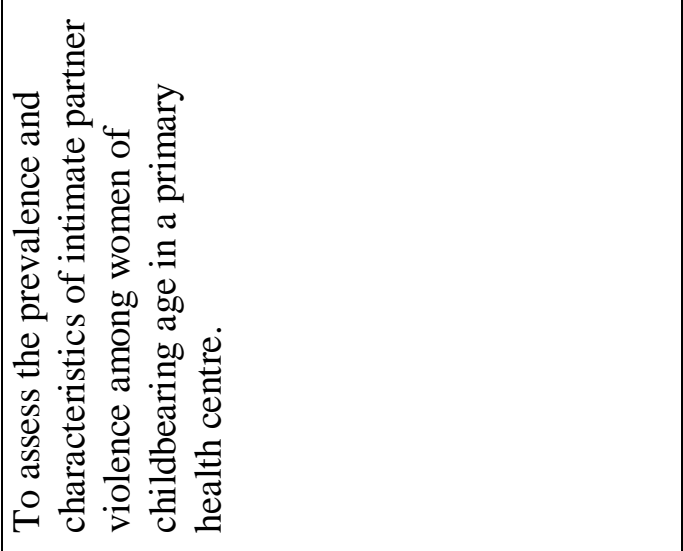 & 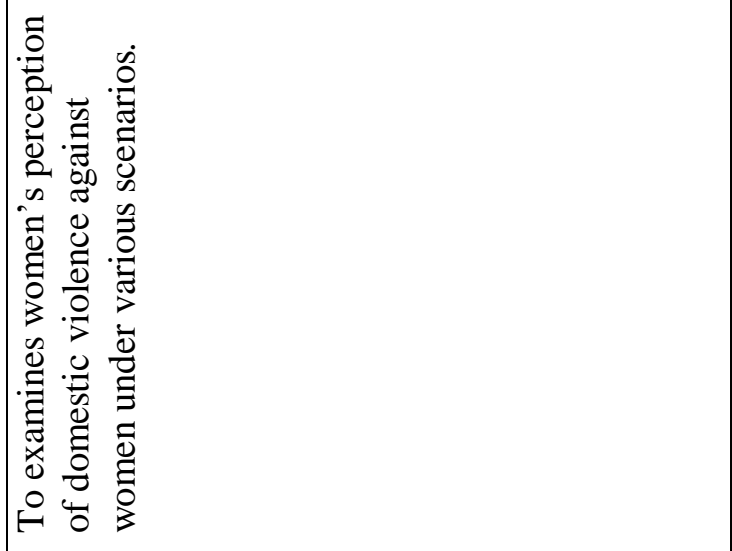 \\
\hline & 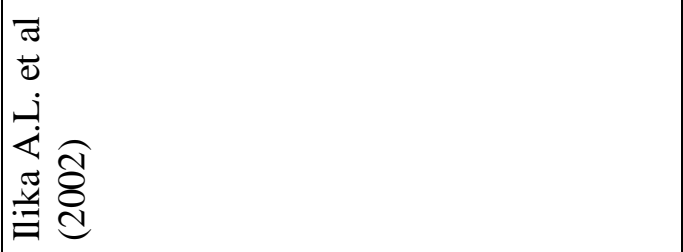 & 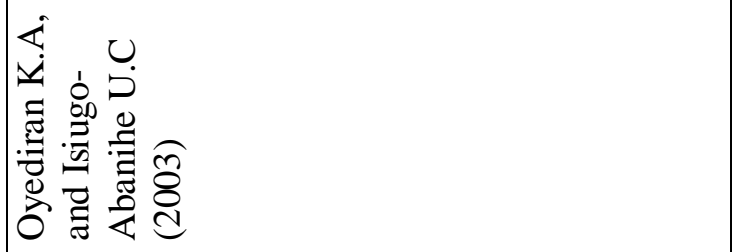 \\
\hline
\end{tabular}




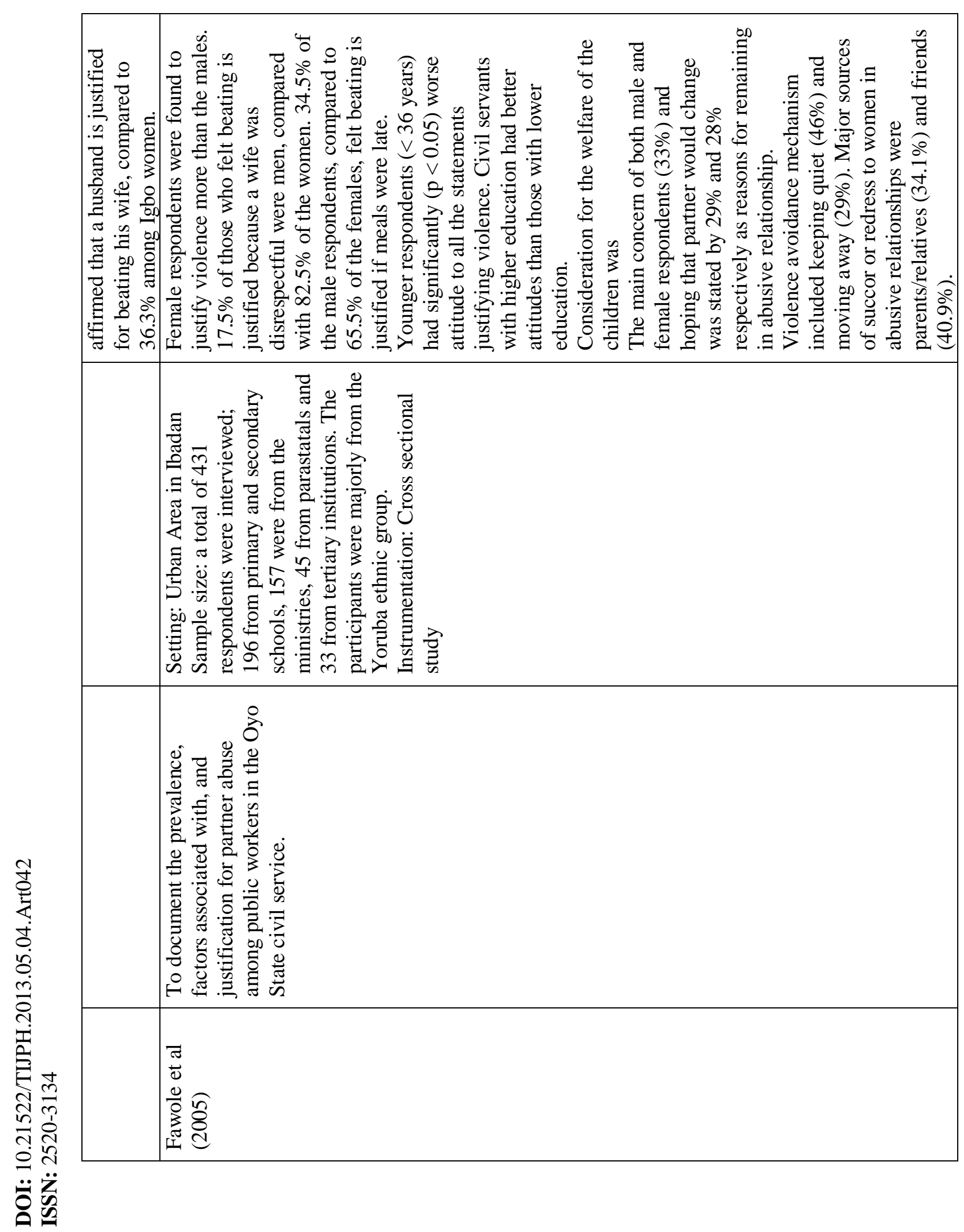




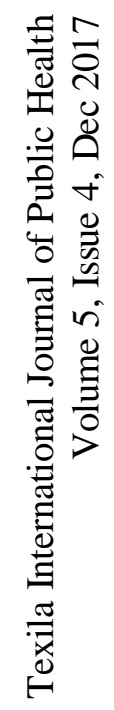

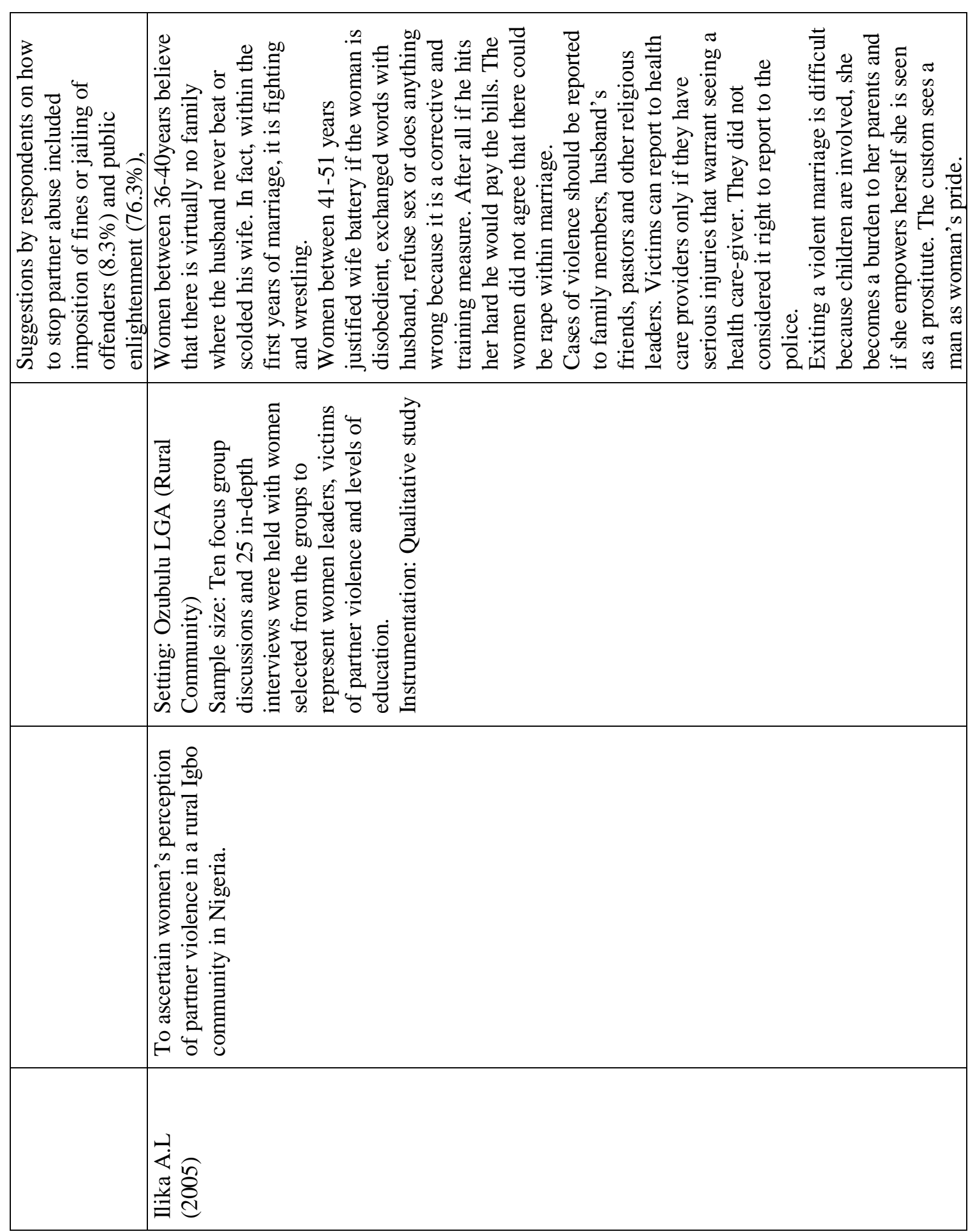




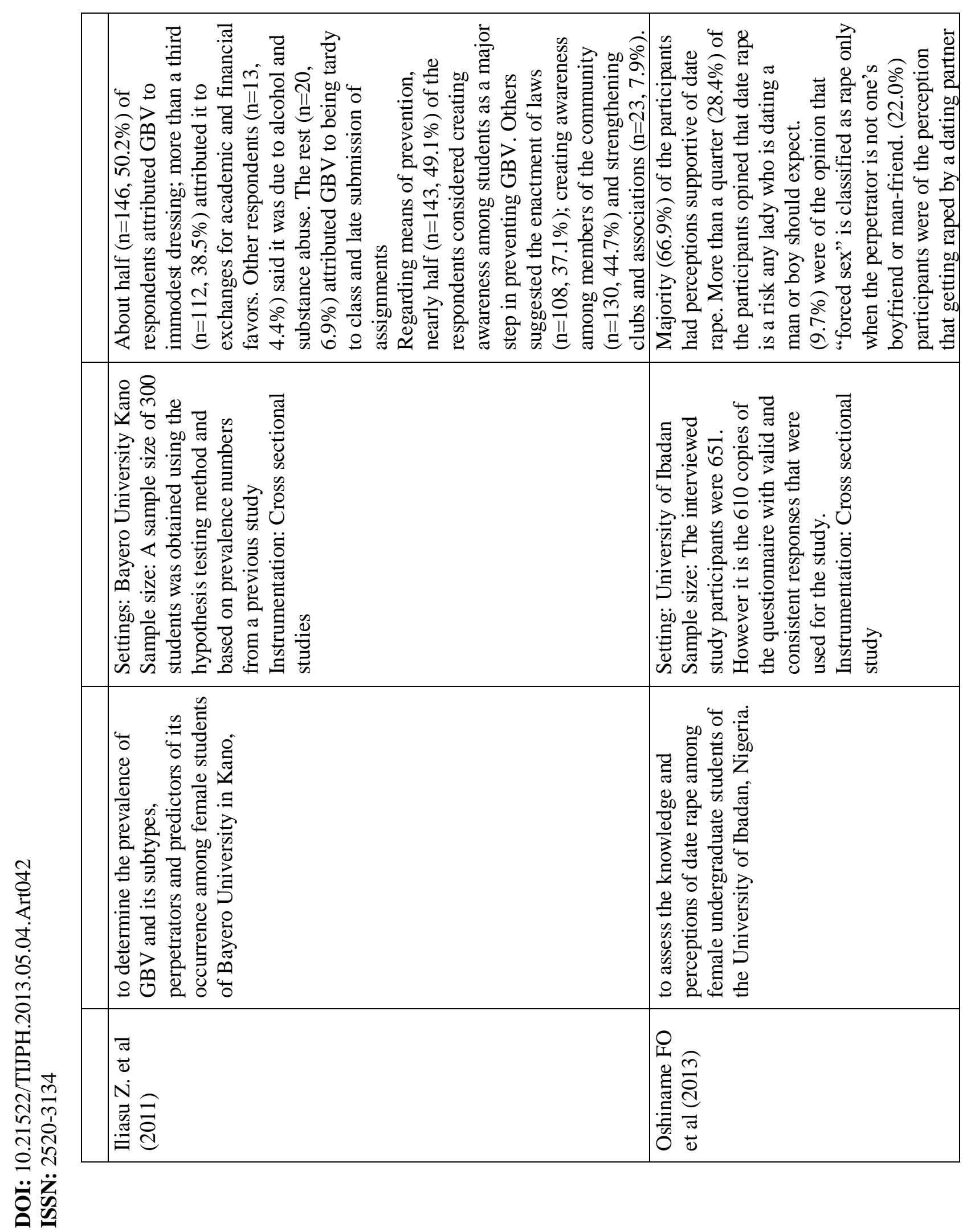




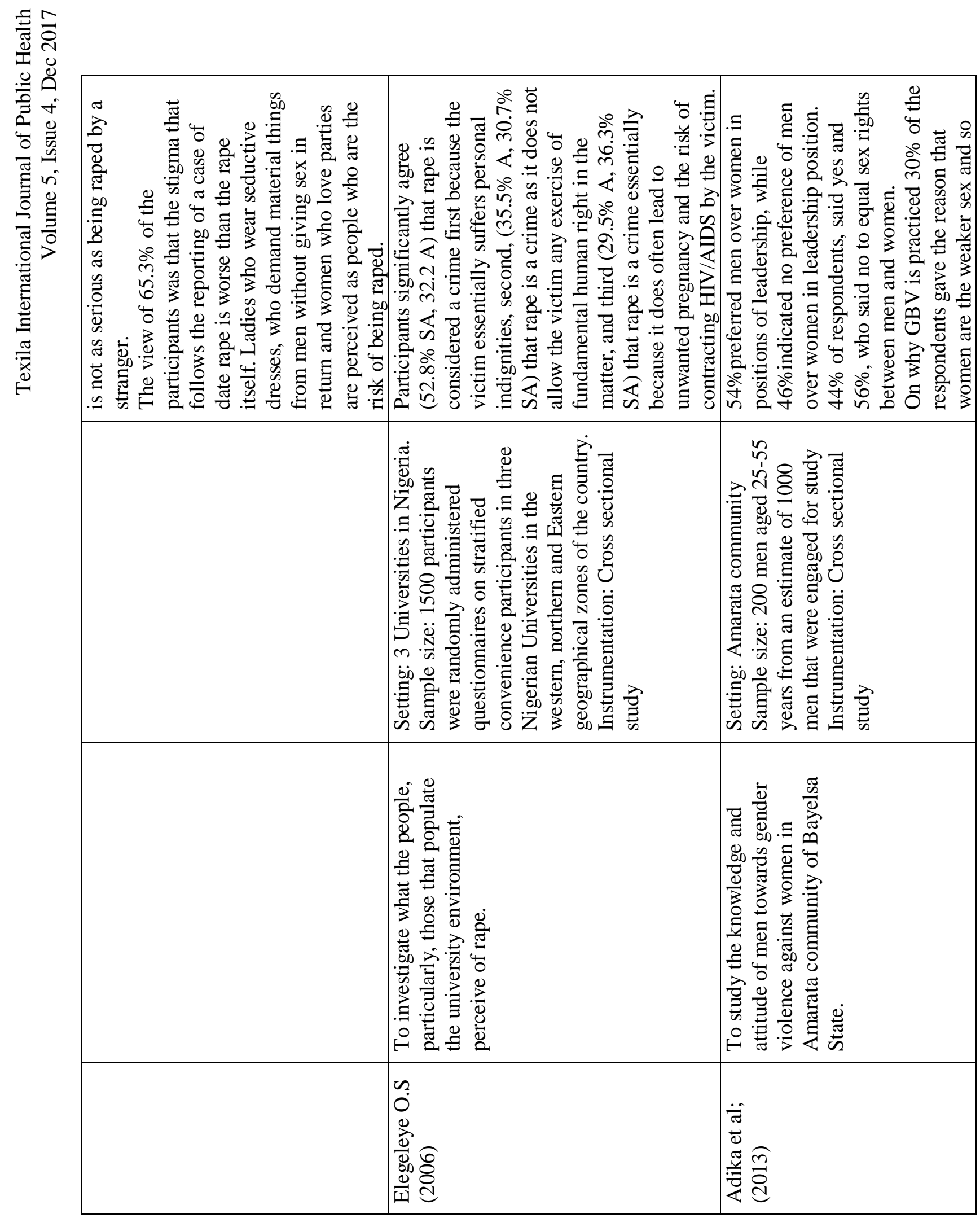




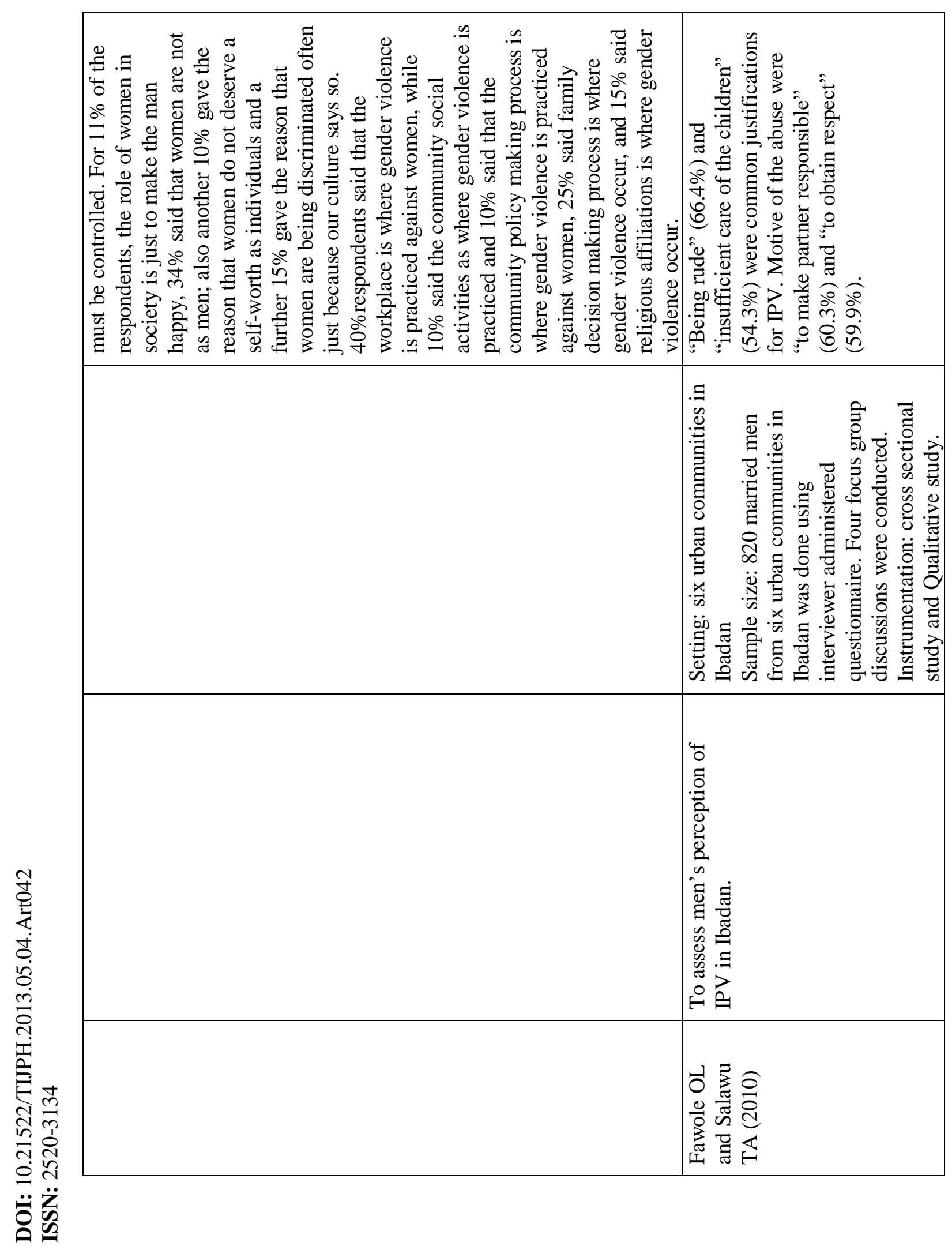




\section{Health impact of gender based violence}

The main findings on the health impact of GBV are illustrated in Table 2. Two of the articles focused on the physical health effect of GBV, one of the articles focused on the perception of the respondents on the health impact of GBV, one on the physical, mental and social health impact of rape on the victims and one of the articles on the mental health effect of gender based violence.

Most of the articles reviewed focused on the health impact of GBV self-reported by the respondents which could have been exaggerated as the objective assessment of the health impact of GBV could not be ascertained in the studies carried out. Despite the limitations observed it is clear that GBV has a negative health impact on the victims. The physical health effect of IPV is minimal compared to the mental health effect that resulted from IPV.

Studies on the common physical health effect of GBV in the six-geopolitical zone of the country show bruises (26\%), injuries, sprains, dislocations or minor burns (12\%), wounds, broken bones, broken teeth or other serious conditions (6\%) and severe burns (6\%) (Antai, 2011). The study carried out by Adebite and Anjuwon (2015) showed sprain, bruises and cuts 59.3\%, Injury and broken bones 32.0\%, Ear block 3.6\%, Threatened abortion $1.1 \%$, Bleeding from the nose $1.5 \%$. IPV in pregnancy according to the perception of the respondents could lead to pregnancy complications such as abortion, premature labor and depression (Efetie and Salami, 2007).

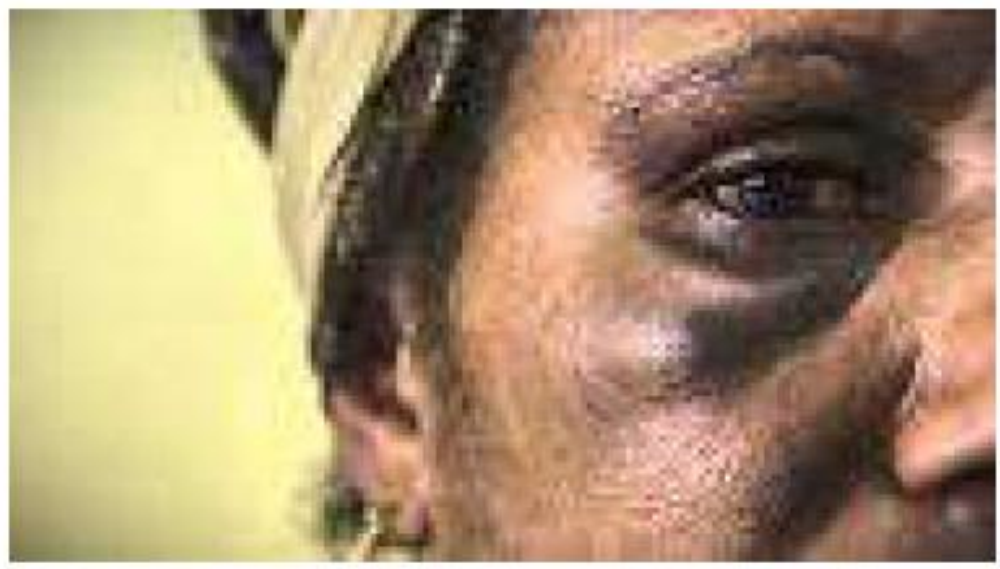

The mental health impact of IPV reported by the respondents include depression (48.8\%), fear and anxiety (31.0\%) and suicidal ideation (11.3\%) which is far more a serious condition than the physical health impact of GBV (Fatusi and Alatise, 2006). The social health impact of IPV is shame the result of the in depth interview by Ilika 2005, He beat me mercilessly and all my face was bruised and battered. I could not go to the market for four days. In addition to the pain and discomfort, I could not stand the anguish and shame of responding to inquisitive neighbors.

The Physical health impact of rape include sexually transmitted infections $38 \%$ followed by unwanted pregnancy $27.5 \%$ and body injuries $13.6 \%$.

The mental health impact \%). Post-Traumatic Stress Disorder (PTSD) accounted for the highest proportion (30.9\%) of psychological effects, followed by depression (25.6\%) and low self-esteem (11.6\%). The social health impact includes stigmatization $23.2 \%$, isolation $20.5 \%$ and poor social relationship $16.3 \%$ (Oshiname et al; 2013). The health seeking attitude by victims of GBV show that majority do not seek for help when violated (Adebite and Anjuwon, 2015). 
DOI: 10.21522/TIJPH.2013.05.04.Art042

ISSN: $2520-3134$

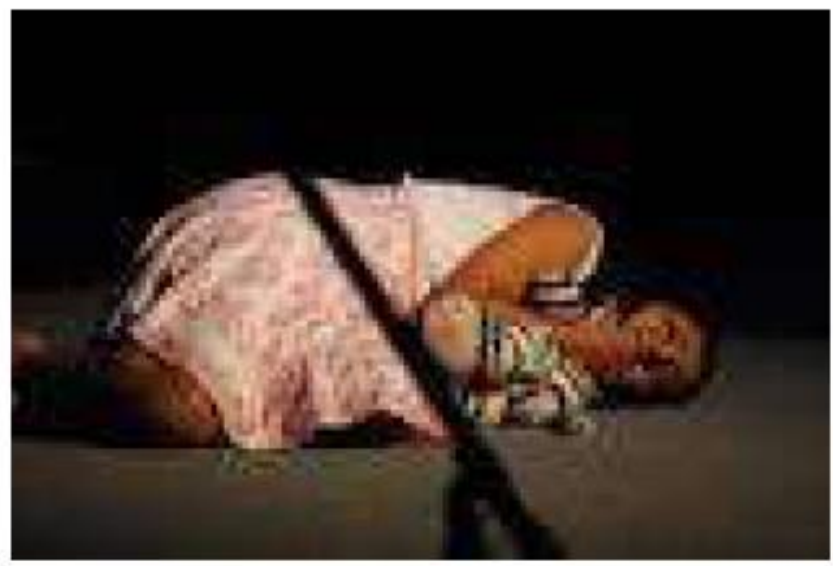



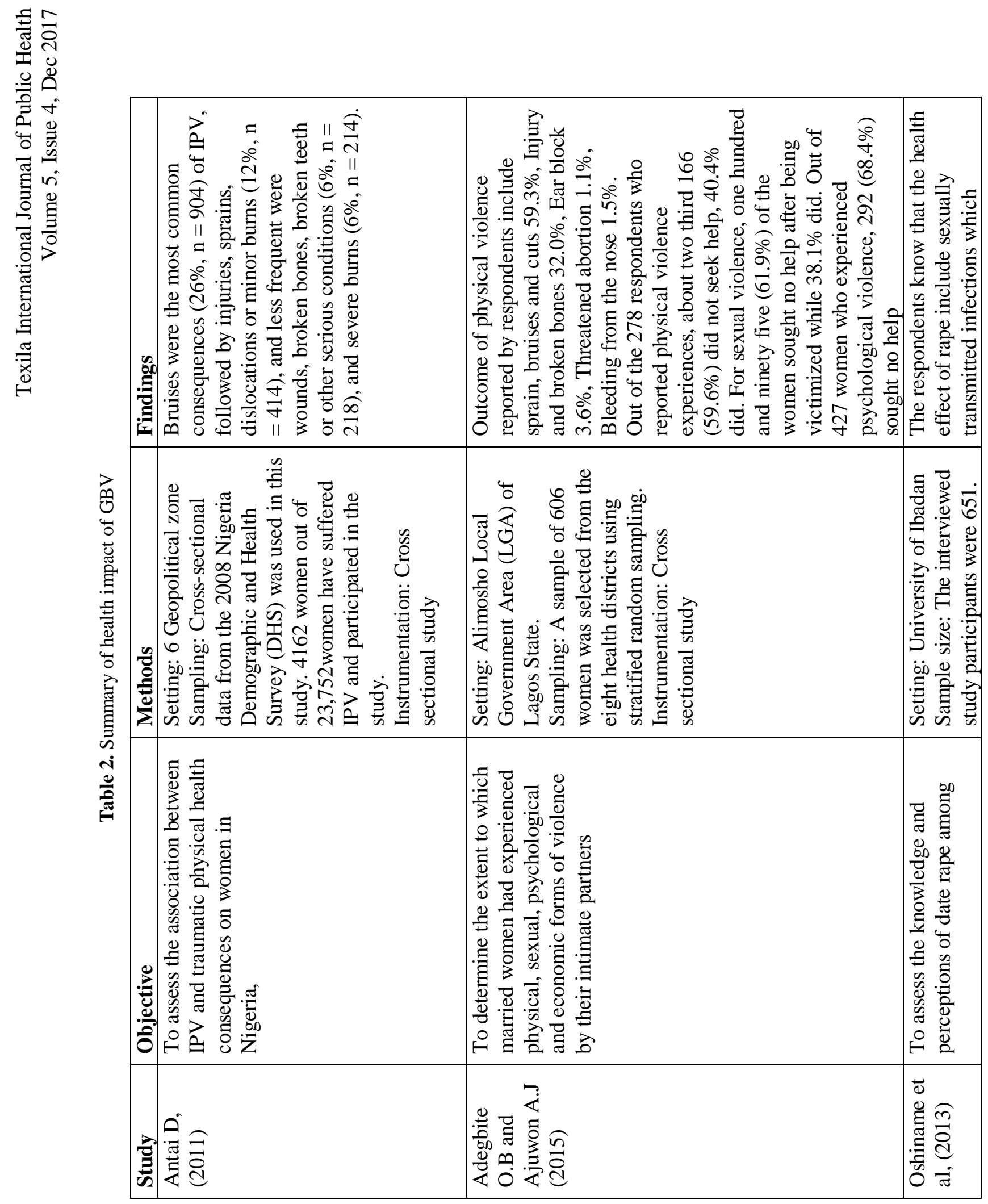


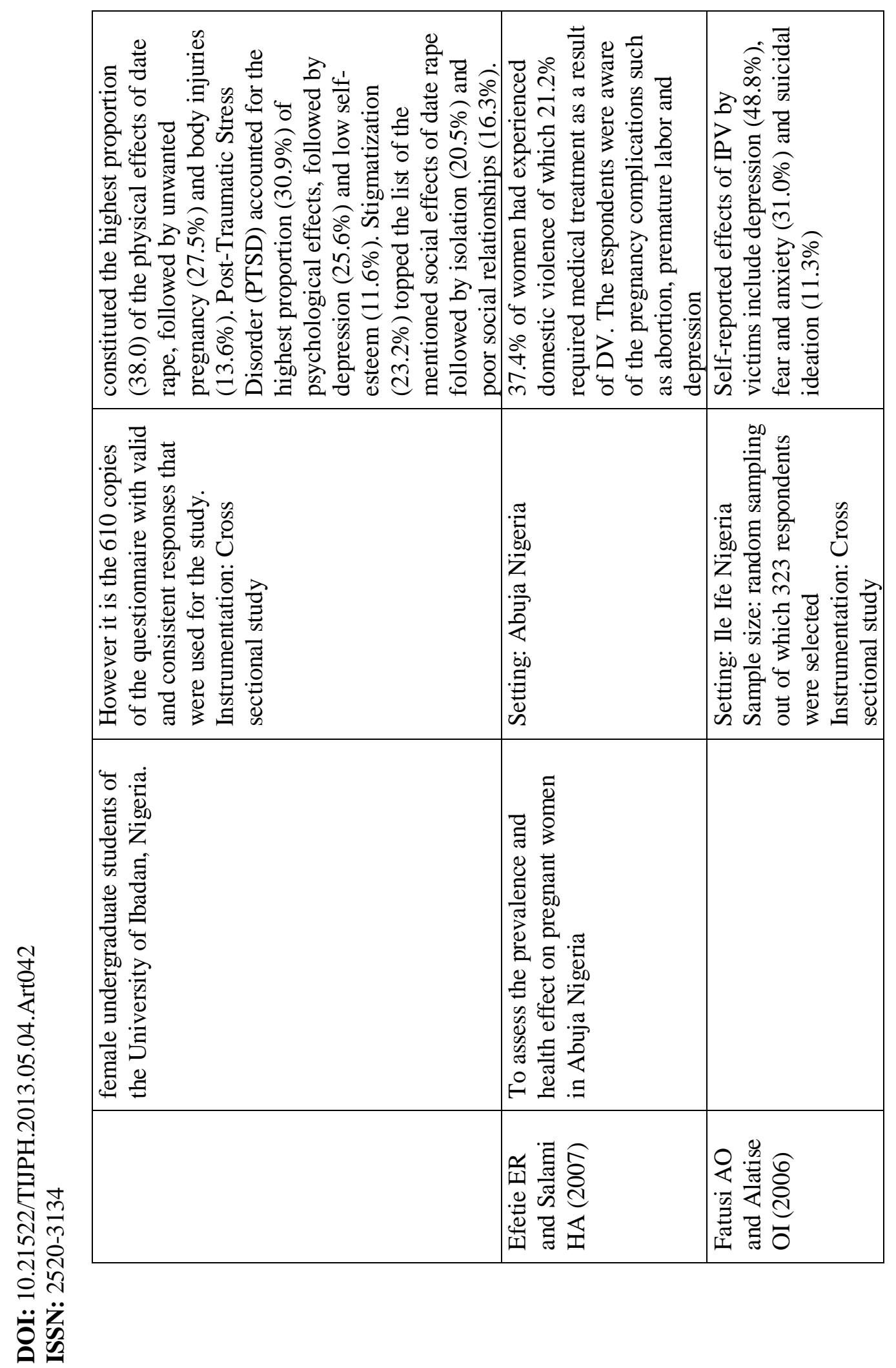




\section{Policy implementation of gender based violence}

The main on policy implementation of GBV in Nigeria is illustrated in Table 3. Only one study was able to evaluate policy implementation of GBV the other study aimed to identify factors that hinders policies against GBV. The study by Ilika and Ilika 2005 demonstrated how policies on GBV is developed and implemented. Although some forms of GBV was eliminated such as not bathing and ritual bathing, drinking of washings from the corpse, most of the GBV were still enforced for a shorter period and practices such as the widow losing her lands due to lack of sons were not abolished in the study. The practices that were abolished have a tendency of being reinstituted due to the fact that there were no sanctions in place to serve as a deterrent. 


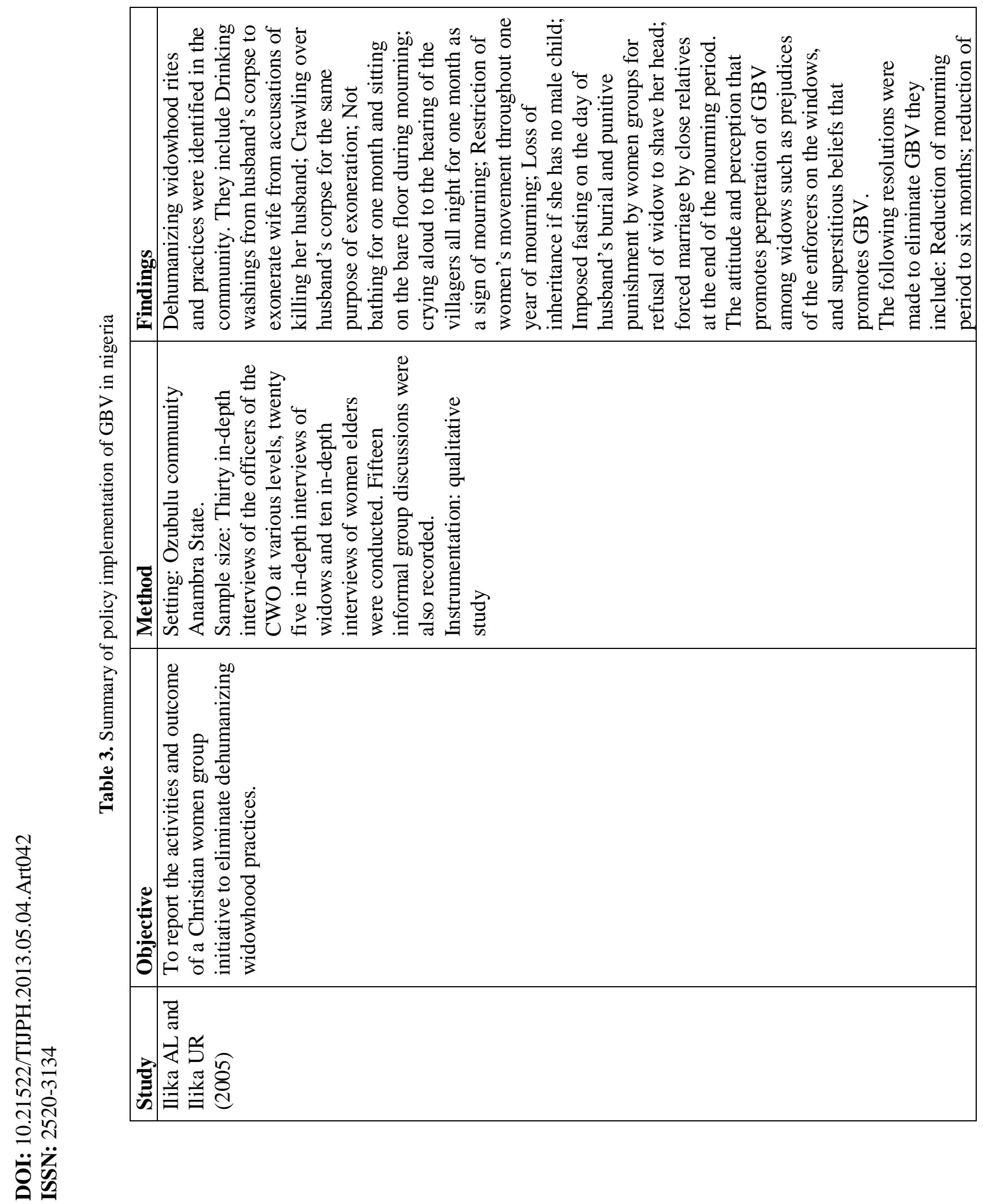



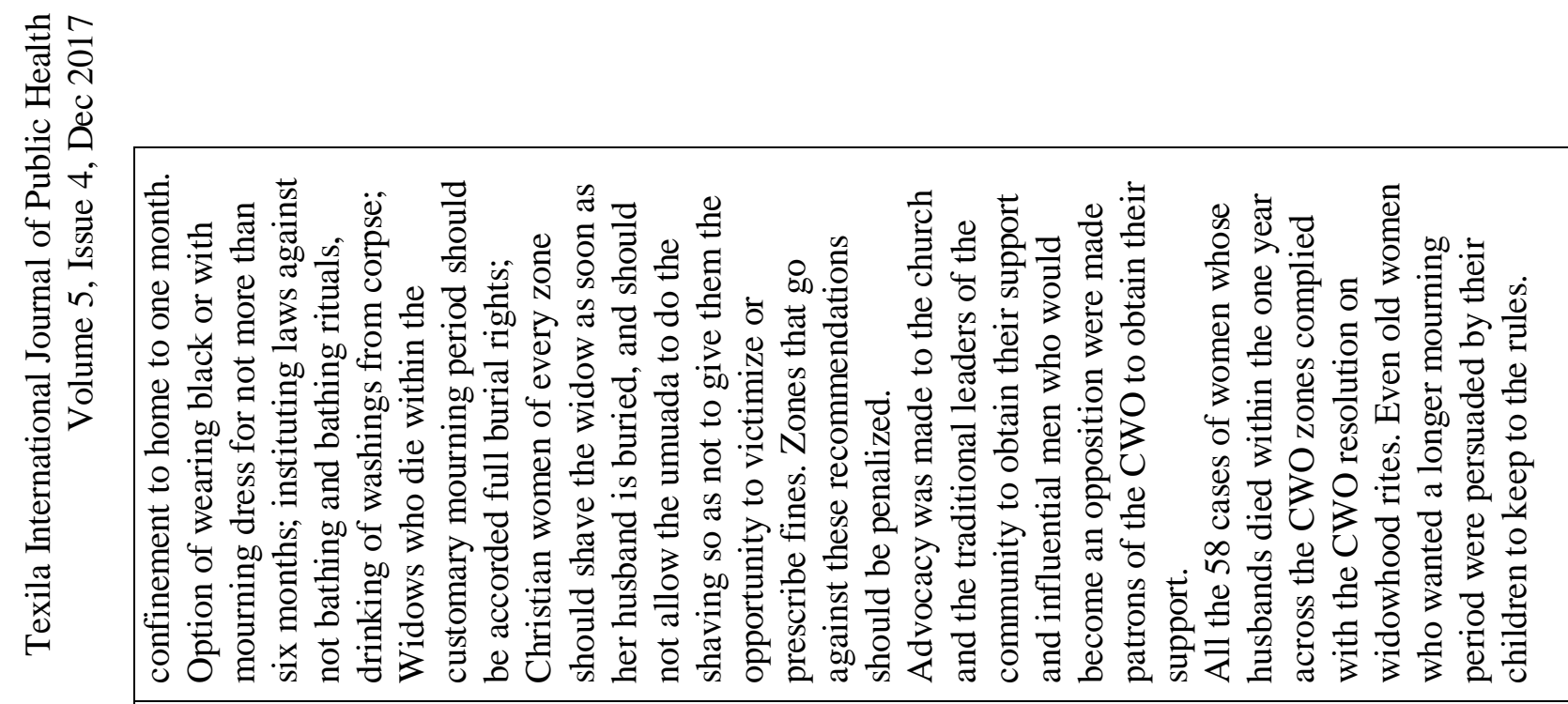
DOI: $10.21522 / \mathrm{TIJPH} .2013 .05 .04 . \mathrm{Art} 042$

ISSN: $2520-3134$

\section{Discussion}

The data set presented in this review is limited; this shows that there is a lot of room for more studies on gender based violence in Nigeria. Despite these limitations it is clear that women are at the greatest risk for violence when they are in their own homes and suggest that GBV programs need to develop innovative strategies for reaching out to victims who suffer GBV in their own homes.

Though most of the women felt that domestic violence is not excusable; the fact that some felt it can be excused under certain conditions or always is rather disturbing. It is equally disturbing that although rape is considered a crime some can justify rape by spouse boyfriends and man friends. Possible theoretical explanations for these acceptance attitudes could include the cognitive dissonance theory, which refers to the distressing mental state in which individuals feel "they find themselves doing things that don't fit with what they know, or having opinions that do not fit with other opinions they hold (Festinger, 1959). These women find themselves trapped in an environment of conflict, and as such, tend to cope with, and make sense of their experiences by accepting violence toward them in certain circumstances. Another plausible explanation for the women's attitude of justifying GBV could be the ecological theory, which is based on multiple, interconnected elements of individuals, communities, institutions, and cultures, and suggests that an individual's behavior is shaped not only by his/her upbringing, but by current contextual factors such as the batterer, reactions he/she receives from those around him/her, and the resources available to him/her. Hence there is need for much work in knowledge improvement to be done to correct this perception. This would be beneficial in reducing the health impact of GBV.

Nigeria, after several decades of ratification of CEDWA, has failed to domesticate the international instrument as part of her municipal law. This regrettably has seriously slowed down the pace of women emancipation in Nigeria. Nigeria is made up many ethnic groups and each ethnic group, operates a peculiar customary law. Most of Nigerian customary laws, especially Igbo customary law are fraught with a legion of gender discriminatory practices. Igbo customary law which operates in South East Nigeria for instance, permits forced/child marriage; wife/girl child disinheritance; polygamy; denies women custodial and maintenance rights, encourages harmful widowhood practices and female genital mutilation (Emakhu, 2013). The Nigerian constitution also legalizes rape gives minimum sentence if assault is perpetuated on a female and legalizes women chastisement. This shows that GBV is being paid lip service hence the reason only one study on the implementation of GBV policy could be found during the search. Despite the limitation, the study by Ilika and ilika 2005 showed that successes can be achieved if community participation is ensured during agenda setting, policy development and policy implementation. Stakeholder analysis was key to the successes achieved in eliminating GBV; this ensured that all anticipated issues were rectified.

\section{Conclusion}

The review has highlighted that there is need for more studies to be done on Gender based violence especially in other forms of GBV. There is also a need for more objective studies on the physical mental and social health impact on gender based violence. Presently in Nigeria, Ebonyi, Jigawa, Cross-Rivers and Lagos states have enacted domestic violence laws. Enugu, Edo, Bayelsa, Delta, Cross-Rivers and Ogun States have also passed laws against female genital mutilation, hence there is a need to evaluate implementation of these laws in this states.

\section{References}

[1]. Adika et al., (2013). Men's attitude and knowledge towards gender based violence against women in Yenagoa, Bayelsa state. Journal of Research in Nursing and Midwifery (JRNM) Vol. 2(6) pp. 77-83.

[2]. Ameh, N., \& Abdul, M. A. (2004). Prevalence of domestic violence amongst pregnant women in Zaria, Nigeria. [3]. Antai, D. (2011). Traumatic physical health consequences of intimate partner violence against women: what is the role of community-level factors?. BMC women's health, 11(1), 56. 
[4]. Antai D and Antai J. (2009), Collective violence and attitudes of women toward intimate partner violence: Evidence from the Niger Delta. BMC International Health and Human Rights 2009

[5]. Antai, D. E., \& Antai, J. B. (2008). Attitudes of women toward intimate partner violence: a study of rural women in Nigeria. Rural Remote Health, 8(3), 996.

[6]. Bott S. and Ellsberg M. (2005), Preventing and responding to gender-based violence in middle and low-income countries: a global review and analysis [Online] Available at http://www.researchgate.net/publication/23723131 Retrieved on: 25 July 2015.

[7]. Efetie, E. R., \& Salami, H. A. (2007). Domestic violence on pregnant women in Abuja, Nigeria. Journal of Obstetrics \& Gynecology, 27(4), 379-382.

[8]. Elegbeleye, O. S. (2006). Is rape in the eye or in the mind of the offender? A survey of rape perception among Nigerian university stakeholders. Educational Research and Review, 1(2), 40-51.

[9]. Fatusi, A. O., \& Alatise, O. I. (2006). Intimate partners' violence in Ile-Ife, Nigeria: women's experiences and men's perspectives. Gender and behaviour, 4(2), p-764.

[10]. Fawole, O. I., Aderonmu, A. L., \& Fawole, A. O. (2005). Intimate partner abuse: wife beating among civil servants in Ibadan, Nigeria. African journal of reproductive health, 54-64.

[11]. Fawole, O. L., Salawu, T. A., \& Olarinmoye, E. O. A. (2010). Intimate partner violence: prevalence and perceptions of married men in Ibadan, Nigeria. International quarterly of community health education, 30(4), 349364.

[12]. Festinger L: A theory of cognitive dissonance. Stanford University, Stanford, Calif; 1957.

[13]. Heise L., Ellsberg M., and Gottmoeller M. (2002), A global overview of gender based violence. International Journal of Gynecology and Obstetrics 78 Suppl. 1 (2002) S5-S14.

[14]. Iliyasu, Z., Abubakar, I. S., Aliyu, M. H., Galadanci, H. S., \& Salihu, H. M. (2011). Prevalence and correlates of gender-based violence among female university students in Northern Nigeria. African journal of reproductive health, 15(3), 123-133.

[15]. Ilika, A. L. (2005). Women's perception of partner violence in a rural Igbo community. African Journal of Reproductive Health, 77-88.

[16]. Ilika, A. L., Okonkwo, P. I., \& Adogu, P. (2002). Intimate partner violence among women of childbearing age in a primary health care centre in Nigeria. African Journal of Reproductive Health, 53-58.

[17]. Mulrow, C. (1994). Systematic reviews. British Medical Journal, 309, 597-599.

[18]. Okemgbo, C. N., Omideyi, A. K., \& Odimegwu, C. O. (2002). Prevalence, patterns and correlates of domestic violence in selected Igbo communities of Imo State, Nigeria. African journal of reproductive health, 101-114.

[19]. Okenwa, L., Lawoko, S., \& Jansson, B. (2011). Contraception, reproductive health and pregnancy outcomes among women exposed to intimate partner violence in Nigeria. The European Journal of Contraception and Reproductive Health Care, 16(1), 18-25.

[20]. Oshiname, F. O., Ogunwale, A. O., \& Ajuwon, A. J. (2013). Knowledge and perceptions of date rape among female undergraduates of a Nigerian university: original article. African journal of reproductive health, 17(3), 137148. Oyediran, K. A., \& Isiugo-Abanihe, U. C. (2005). Perceptions of Nigerian women on domestic violence: Evidence from 2003 Nigeria Demographic and Health Survey. African journal of reproductive health, 38-53.

[21]. Pico-Alfonso et al, (2006), The Impact of Physical, Psychological, and Sexual Intimate Male Partner Violence on Women's Mental Health: Depressive Symptoms, Posttraumatic Stress Disorder, State Anxiety, and Suicide. Journal of women's health Vol. 15, No 5 pp 599-608.

[22]. Uwamieye B.E., Iserameiya F.E, (2013), Gender Based Violence against Women and Its Implication on the Girl Child Education in Nigeria. Inter. Journ. of Academic Research in Progressive Education and Development January 2013, Vol. 2, No. 1 ISSN: 2226-6348 Pp 219-225. 